\title{
Acromegaloid Facial Appearance Syndrome - A New Case in India
}

\author{
Arpita Rai ${ }^{1 *}$, Atul P Sattur ${ }^{2}$ and Venkatesh G Naikmasur ${ }^{2}$ \\ ${ }^{1}$ Department of Oral Medicine and Radiology, Faculty of Dentistry, Jamia Millia Islamia New Delhi, India \\ ${ }^{2}$ Department of Oral Medicine and Radiology, S.D.M. College of Dental Sciences \& Hospital, Dharwad Karnataka, India
}

\begin{abstract}
Acromegaloid Facial Appearance syndrome is a very rare syndrome combining acromegaloid-like facial appearance, thickened lips and oral mucosa and acral enlargement. Progressive facial dysmorphism is characterized by a coarse facies, a long bulbous nose, high-arched eyebrows, and thickening of the lips, oral mucosa leading to exaggerated rugae and frenula, furrowed tongue and narrow palpebral fissures. We report a case of acromegaloid facial appearance syndrome in a 19-year-old male patient who presented with all the characteristic features of the syndrome along with previously unreported anomalies like dystrophic nails, postaxial polydactyly and incisal notching of teeth.
\end{abstract}

Key words: Acromegaloid Facial Appearance Syndrome, Hughe's syndrome, polydactyly

\section{Introduction}

Acromegaloid facial appearance syndrome (AFA syndrome, OMIM 102150), an extremely rare congenital syndrome primarily characterized by progressively coarse acromegaloid-like facial appearance with thickening of the lips and oral mucosa. The syndrome was first recognized by Hughes et al. in 1985 in large kindred with affected relatives spanning at least five generations." This case features the tenth report of this syndrome wherein anomalies like dystrophic nails, postaxial polydactyly and incisal notching of teeth, not previously described with this syndrome were also present. A brief review of previously reported cases and discussion of differential diagnosis of the syndrome is presented.

\section{Case Report}

A 19-year-old male patient reported to the Department of Oral Medicine and Radiology with routine dental complaints. Patient gave history of progressive coarsening of facial features and thickening of lips. Patient was one of the two siblings of nonconsanguineous parents with no family history of such or any other congenital abnormalities. The patient's birth was a result of a uncomplicated cesarean delivery. Antenatal and neonatal history and infancy were uneventful. Developmental milestones were not delayed and he had no history of learning disability. Routine general physical examination revealed moderately built, well nourished male who appeared to have normal intelligence and was otherwise in good health. Patient's height was $164 \mathrm{~cm}$, weight $45 \mathrm{~kg}$ and head circumference was 22 inch. Craniofacial manifestations comprised of thick patulous lips, bulbous nose with a broad base, prominent philtrum, mandibular prognathism

\footnotetext{
Received: 18 May 2013, Revised: 9 June 2013, Accepted: 12 June 2013, Published: 30 June 2013

${ }^{*}$ Corresponding author: Arpita Rai

Department of Oral Medicine and Radiology, Faculty of Dentistry, Jamia Millia Islamia, New Delhi-110025, India

Tel: +918362467612, Fax: +918802536376, E-mail: arpitadoc@gmail.com

(c) This is an open-access article distributed under the terms of the Creative Commons Attribution Non-Commercial License (http://creativecommons.org/licenses/by-nc/3.0/) which permits unrestricted non-commercial use, distribution, and reproduction in any medium, provided the original work is properly cited.

(c) Copyright 2013 by the Korean Society of Medical Genetics 


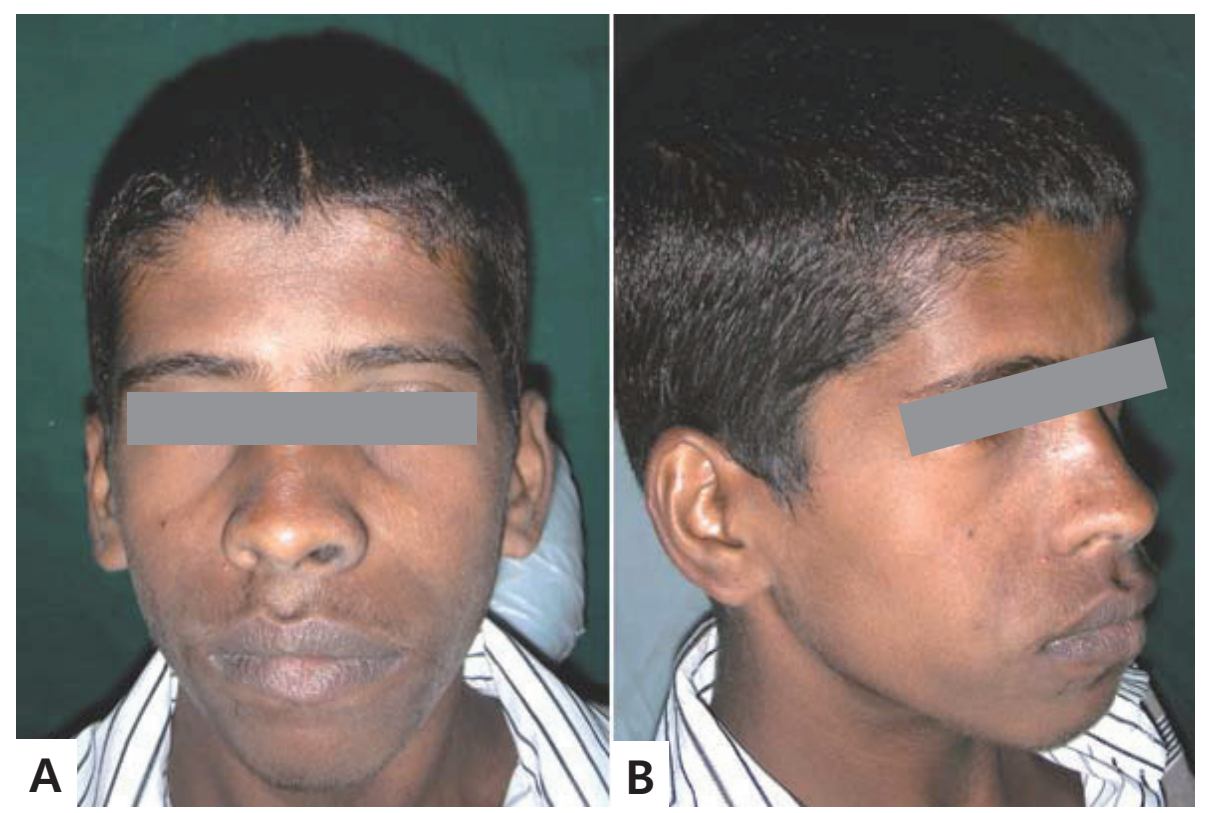

Fig. 1. (A) Clinical photograph of patient showing craniofacial manifestations of thick patulous lips, bulbous nose with a broad base, prominent philtrum, mandibular prognathism, narrowed palpebral fissures and mild facial asymmetry. (B) Clinical photograph of patient showing posteriorly angulated ears with enlarged Darwin tubercle.
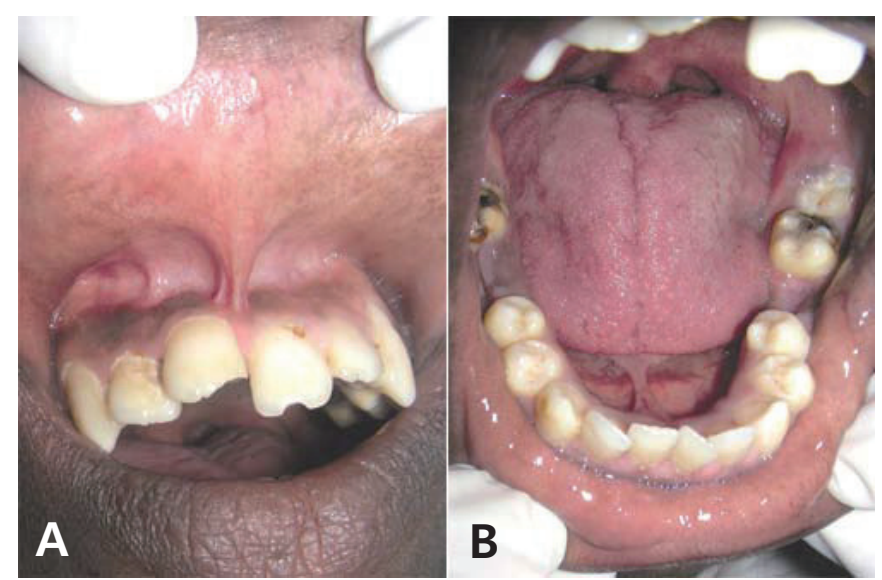

Fig. 2. Intraoral photograph of the patient showing hyperplastic upper labial $(A)$ and lingual frenula (B) and incisal notching of upper anterior teeth.

and narrowed palpebral fissures (Fig. 1A). There was mild facial asymmetry with left side of face appearing generally enlarged as compared to the right side. Enlarged Darwin's tubercle could be demonstrated in both the auricle and ears were posteriorly angulated (Fig. 1B). Intraoral thickened intraoral mucosa with exaggerated rugae and high arched palate was observed. Upper labial (Fig. 2A) and lingual frenula were hyperplastic (Fig. 2B) and a furrowed enlarged tongue with prominent fungiform papillae was noticed (Fig. 3A). Uvula was elongated (Fig. 3B). Crowding of teeth in both the arches and multiple decayed teeth were seen. One striking feature which was evident in the patient was incisal notching of maxillary incisor, mainly 11,21 and 22 (Fig. 2A).

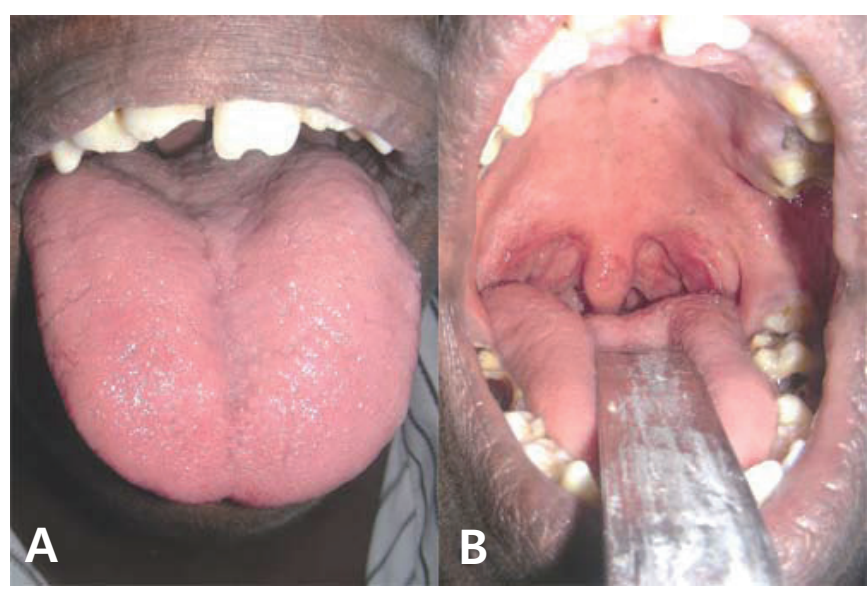

Fig. 3. (A) Intraoral photograph showing enlarged tongue with prominent fungiform papillae. (B) Intraoral photograph showing elongated uvula.

The other characteristic finding of the patient was acral enlargement. Both hands and feet of the patient were large, spade-like and disproportionate to his height (Fig. 4A). The consistency of the overlying skin was normal. Post axial polydactyly of left foot was observed wherein the supernumerary digit presented as a rudimentary 6th toe attached to the foot by soft tissue only (Fig. 5A). Nails of both hands and feet were dystrophic. In hands spoon shaped nails with vertical streaks were seen (Fig. 4B) while those of feet showed even more irregularity (Fig. 5A).

Routine laboratory investigations (including hemogram and random blood sugar), thyroid function \& growth hormoneassay $(0.9 \mathrm{ng} / \mathrm{mL})$ were normal. A radiographic skeletal survey did not 


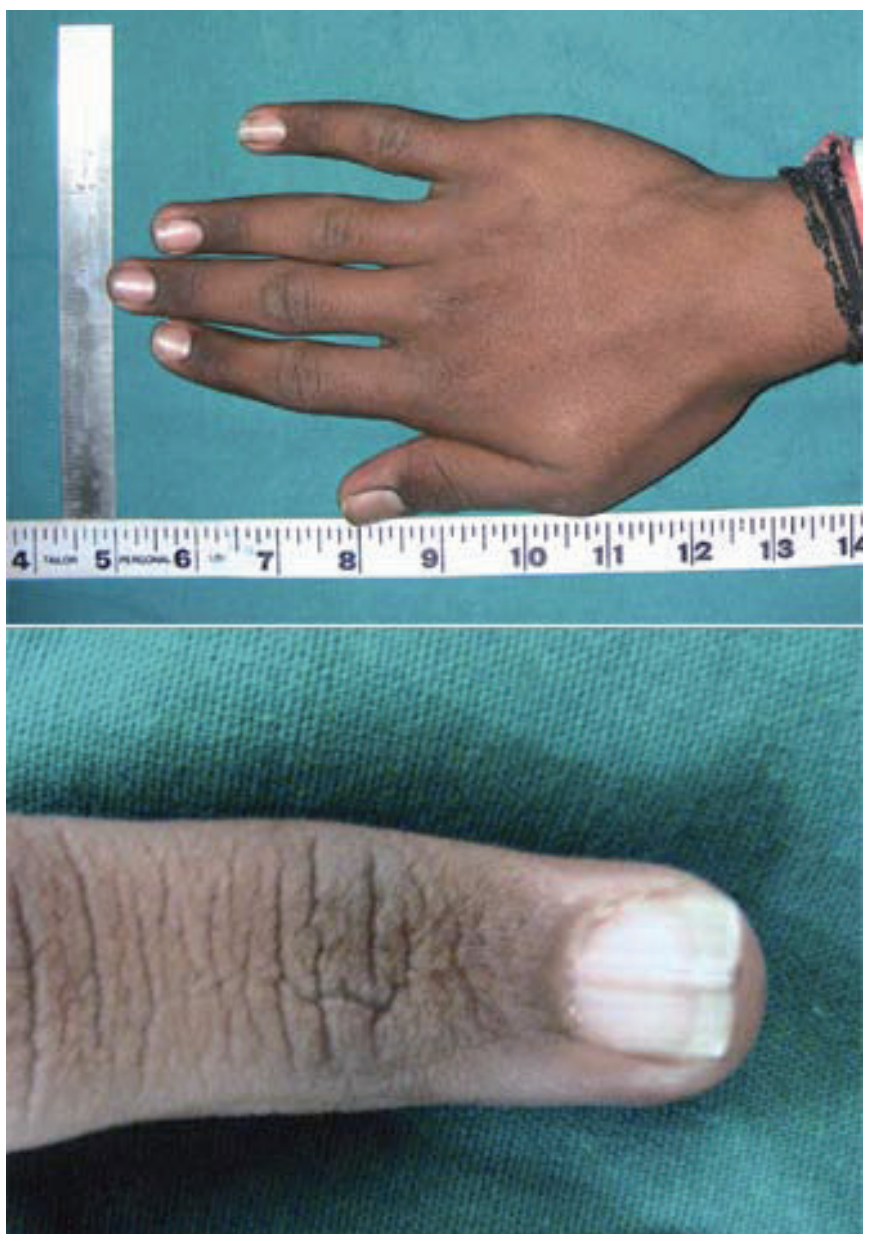

Fig. 4. Large spade-like hand with spoon shaped nails and vertical streaks.

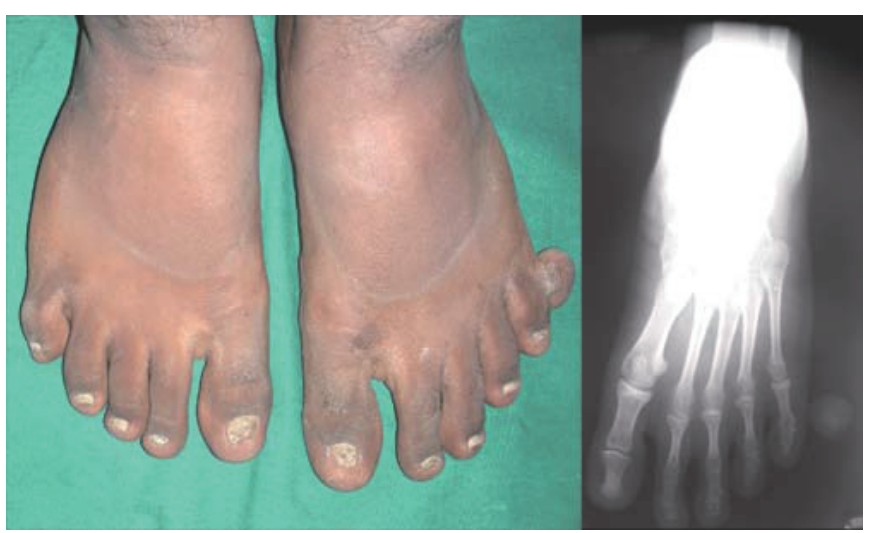

Fig. 5. Enlarged feet and postaxial polydactyly of left foot with dystrophic nails.

show any characteristic anomaly; however A-P feet radiograph revealed rudimentary supernumerary toe in postaxial position exhibiting soft tissue syndactyly with 5th toe (Fig. 5B).

\section{Discussion}

Acromegaloidism describes a highly heterogeneous group of disorders. When a patient presents with acromegaloid phenotype in early adulthood, growth hormone excess and insulin resistance associated pseudoacromegaly should be first ruled out by analyzing the endocrine profile of the patient. On exclusion of an abnormality of the somatotrophic axis, rare genetic syndromes associated with the AFA should be considered in the differential diagnosis. The AFA has been reported in association with pachydermoperiostosis (an osteo-arthro-dermopathic syndrome), generalized hypertrichosis on two separate occasions, keratitis in a Kirghizian family, and cutis verticis gyrata. ${ }^{2-6)}$

The AFA syndrome has also been associated with thickened oral mucosa and is known as Hughes syndrome after the first case report presented by Hughes et al. in 1985, ${ }^{1)}$ who described a syndrome of acromegaloid facial features: thickened lips (without a true 'double lip'), overgrowth of the intraoral mucosa resulting in exaggerated rugae and frenula, and thickened upper eyelids leading to narrow palpebral fissures (blepharophimosis) in many members of a kindred through at least 5 generations. Since then few case reports of AFA syndrome have been published so far in world literature. This case represents the tenth report of the syndrome. Summary of previously reported of this syndrome is provided in Table 1.

The patient presented with typical features of the syndrome. Normal endocrine profile ruled out possibility of acromegaly or pseudoacromegaly. Absence of cutaneous and radiographic findings like papular mucinosis, hyperkeratosis, generalized hypertrophy of epidermal appendages and periosteal thickening of skull or the long bones ruled out pachydermoperiostosis. Features of keratitis, cutis verticis gyrate and associated abnormalities were noted for their absence.

The present case not only exemplified characteristic features of AFA syndrome but also presented with features like notching of maxillary anteriors, elongated uvula, dystrophic nails and postaxial polydactyly of left foot; which have never been reported previously in literature in association with AFA syndrome.

Etiology for AFA syndrome is unknown. No chromosomal abnormality or genetic locus has been described in this syndrome. Low positive lod scores were obtained for linkage between AFA and $R h$ and PGM1 (on ch.1p), GLO (on ch.6p), IGHG and PI (on ch.14q), and $H P$ (on ch.16q).) It usually segregates in an autosomal dominant fashion. Despite wide phenotypic variability, this autosomal dominant mutation showed complete penetrance in the series repo rted by Hughes et al." and Dallapiccola et al." ${ }^{7}$ while 
Table 1. Summary of Reported Case of Acromegaloid Facial Appearance Syndrome

\begin{tabular}{|c|c|c|c|c|}
\hline Case no. & Reference & Year & Inheritance & Manifestations \\
\hline 1. & Hughes et al. $^{1}$ & 1985 & $\begin{array}{l}\text { Autosomal dominant (AD) } \\
\text { with complete penetrance }\end{array}$ & $\begin{array}{l}\text { Progressively coarse facial appearance, thickened lips, exaggerated rugae and } \\
\text { frenula, furrowed tongue, narrow palpebral fissures, bulbous nose, high arched } \\
\text { eyebrows and large doughy hands with joint laxity }\end{array}$ \\
\hline 2. & Dallapiccola et al. ${ }^{7}$ & 1992 & $\begin{array}{l}\text { AD with complete } \\
\text { penetrance }\end{array}$ & $\begin{array}{l}\text { Progressively coarse acromegaloid-like facial appearance, narrow palpebral } \\
\text { fissures, bulbous nose, thickening of the lips, exaggerated rugae and frenula, } \\
\text { furrowed tongue, large hands, increased birth weight and dull mentality. }\end{array}$ \\
\hline 3. & Irvine et al. ${ }^{3}$ & 1996 & $A D$ & $\begin{array}{l}\text { Family with phenotype of acromegaloid facial appearance and generalised } \\
\text { hypertrichosis terminalis segregated through three generations. }\end{array}$ \\
\hline 4. & Da-Silva et al. ${ }^{8}$ & 1998 & Isolated occurence & $\begin{array}{l}\text { Coarse facies, thickened lips, oral mucosa and upper eyelids and macrocephaly } \\
\text { with arachnoid cyst }\end{array}$ \\
\hline 5. & Stratakis et al. ${ }^{10}$ & 2001 & $\begin{array}{l}\text { AD with Incomplete } \\
\text { penetrance }\end{array}$ & $\begin{array}{l}\text { Family with variable clinical expression of acromegaloidism associated with other } \\
\text { developmental defects }\end{array}$ \\
\hline 6. & Zelante et al. ${ }^{11}$ & 2000 & Unknown & $\begin{array}{l}\text { Coarse facies, bulbous nose, thickened lips, narrow palpebral fissure, thickened } \\
\text { intraoral mucosa, large hands with pericardial effusion and skin lesions }\end{array}$ \\
\hline 7. & Zen et al. ${ }^{4}$ & 2004 & Autosomal recessive & Coarse facial features with hypertricosis \\
\hline 8. & Kini et al. ${ }^{9}$ & 2004 & $\begin{array}{l}\text { AD with incomplete } \\
\text { penetrance }\end{array}$ & $\begin{array}{l}\text { Progressively coarse acromegaloid-like facial appearance with thickening of the } \\
\text { lips and gums and severe learning difficulties. }\end{array}$ \\
\hline 9. & Ghazi et al. ${ }^{12}$ & 2013 & $\begin{array}{l}\text { AD with incomplete } \\
\text { penetrance }\end{array}$ & $\begin{array}{l}\text { Coarse facies with thick facial skin, broad bulbous nose, deep nasolabial folds, } \\
\text { marked furrows of the brow, blepharophimosis, drooping of eyelids, high arched } \\
\text { eyebrows, thickened lower lip, and torus palatinus. Increased hair growth on upper } \\
\text { lip, chin, and coarse terminal hair of arms and legs. }\end{array}$ \\
\hline 8. & Present case & 2013 & Isolated occurence & $\begin{array}{l}\text { Thick lips, bulbous nose, prominent philtrum, mandibular prognathism, narrowed } \\
\text { palpebral fissures, exaggerated rugae, hyperplastic frenula, enlarged furrowed } \\
\text { tongue, elongated uvula, incisal notching of teeth, acral enlargement, dystrophic } \\
\text { nails and post axial polydactyly of left foot }\end{array}$ \\
\hline
\end{tabular}

case reported by Kini and Clayton-Smith suggested autosomal dominant inheritance with incomplete penetrance. ${ }^{9)}$ The present case represents the second instance of isolated occurrence of this condition.

No specific medical follow-up is required for patients suffering from this syndrome, as no complication has been described. The coarsening of facial features may be of esthetic concern to the patient and may warrant a referral to dentist. It is necessary to rule out endocrinal abnormalities in these patients before establishing the diagnosis of AFA syndrome. Craniofacial manifestations including intraoral findings are mainstay for diagnosing this syndrome. Routine dental care, proper maintenance of oral hygiene and cleaning of tongue between the furrows with a toothbrush may be advised. Orthodontic consultation regarding mandibular prognathism should be sought. Facial cosmetic surgery may be considered in full-blown cases of AFA syndrome patients.

\section{References}

1. Hughes HE, McAlpine PJ, Cox DW, Philipps S. An autosomal dominant syndrome with 'acromegaloid' features and thickened oral mucosa. J Med Genet 1985;22:119-25.

2. Harbison JB, Nice CM Jr. Familial pachydermoperiostosis presenting as an acromegaly-like syndrome. Am J Roentgenol Radium Ther Nucl Med 1971;112:532-6.

3. Irvine AD, Dolan OM, Hadden DR, Stewart FJ, Bingham EA, Nevin NC. An autosomal dominant syndrome of acromegaloid facial appearance and generalized hypertrichosis terminalis. J Med Genet 1996;33:972-4.

4. Zen PR, Schwartz IV, Paskulin GA. Acromegaloid facial appearance and hypertrichosis: a case suggesting autosomal recessive inheritance. Clin Dysmorphol 2004;13:49-50.

5. Kozlova SI, Altshuler BA, Kravchenko VL. Self-limited autosomal recessive syndrome of skin ulceration, arthroosteolysis with pseudoacromegaly, keratitis, and oligodontia in a Kirghizian family. Am J Med Genet 1983;15:205-10.

6. Rosenthal JW, Kloepfer HW. An acromegaloid, cutis verticis gyrata, corneal leukoma syndrome. A new medical entity. Arch Ophthalmol 1962;68:722-6.

7. Dallapiccola B, Zelante L, Accadia L, Mingarelli R. Acromegaloid facial appearance (AFA) syndrome: report of a second family. J Med Genet 1992;29:419-22.

8. da-Silva EO, Duarte AR, Andrade EJ, Furtado GJ. A new case of the acromegaloid facial appearance syndrome? Clin Dysmorphol 1998;7: 75-6.

9. Kini U, Clayton-Smith J. Acromegaloid facial appearance syndrome: a further case report. Clin Dysmorphol 2004;13:251-3.

10. Stratakis CA, Turner ML, Lafferty A, Toro JR, Hill S, Meck JM, et al. A syndrome of overgrowth and acromegaloidism with normal growth 
hormone secretion is associated with chromosome 11 pericentric inversion. J Med Genet 2001;38:338-43.

11. Zelante L, Gasparini P, Savoia A, Lomuto M, Pellicano R. A new case of acromegaloid facial appearance (AFA) syndrome with an expanded phenotype. Clin Dysmorphol 2000;9:221-2.

12. Ghazi A, Khosla S, Becker K. Acromegaloid Facial Appearance: case report and literature review. Case Rep Endocrinol 2013;2013:970396. 